\title{
An observational study of initial HIV RNA decay following initiation of combination antiretroviral treatment during pregnancy
}

Jasmini Alagaratnam ${ }^{1,2,3^{*}}$ (], Helen Peters ${ }^{4}$, Kate Francis ${ }^{4}$, Natasha Kay ${ }^{5}$, Yvonne Gilleece ${ }^{6}$, Fionnuala P. Finnerty ${ }^{6}$, Rosanna E. Grimes ${ }^{6}$, Sarah Parry ${ }^{7}$, Mags Portman ${ }^{7 \wedge}$, Brenton C. Wait ${ }^{7}$, Rimi Shah ${ }^{8}$, Sherie Roedling ${ }^{9}$, David A. Hawkins ${ }^{10}$, Sarah Chitty ${ }^{10}$, Liat Sarner ${ }^{11}$, Rebecca Marcus ${ }^{11}$, Anna Hartley ${ }^{11}$, Achyuta V. Nori ${ }^{12}$, Melanie Rosenvinge ${ }^{13}$ and Graham P. Taylor ${ }^{1,2}$ on behalf of the London HIV Perinatal Research Group

\begin{abstract}
Background: In pregnancy, reduction of HIV plasma viral load (pVL) for the prevention of vertical transmission is time-constrained. The study primary objective is to investigate factors associated with faster initial HIV RNA half-life decay when combination antiretroviral treatment (CART) is initiated in pregnancy.

Methods: This was a multicentre, retrospective, observational study, conducted in south England, United Kingdom, between August 2001 and February 2018. Data were extracted from case notes of eligible women initiating cART during the index pregnancy. Anonymised data were collated and analysed centrally. Regression analyses were conducted to determine factors associated with faster HIV RNA half-life decay in the first 14 days after commencing cART (firstphase), and with achieving an undetectable maternal pVL by 36 weeks' gestation. We then assessed whether HIV-and obstetric- related parameters differed by antiretroviral third agent class and whether the proportions of women with undetectable pVL at 36 weeks' gestation and at delivery differed by antiretroviral third agent class.
\end{abstract}

Results: Baseline pVL was the only independent factor associated with faster first-phase HIV RNA half-life decay on commencing CART. Lower pVL on day 14 after starting CART was associated with an increased likelihood of achieving an undetectable pVL by 36 weeks' gestation. Integrase inhibitor-based cART was associated with a faster first-phase HIV RNA half-life decay on commencing CART. Overall, $73 \%$ and $85 \%$ of women had an undetectable pVL at 36 weeks' gestation and at delivery respectively, with no significant difference by antiretroviral third agent class.

Conclusions: Only high baseline pVL independently contributed to a faster rate of first-phase viral half-life decay. pVL at 14 days after initiating CART allows early identification of treatment failure. In the first 14 days after initiating CART in pregnancy, integrase inhibitor-based cART reduced maternal pVL faster than protease inhibitor- and non-nucleoside reverse transcriptase-based cART. While our study findings support INSTI use when initiated in pregnancy especially when initiated at later gestations and in those with higher baseline PVL, other non-INSTI based CART with more data on safety in pregnancy also performed well.

Keywords: Antiretroviral therapy, Monitoring, Novel observations, Treatment outcomes

*Correspondence: j.alagaratnam@imperial.ac.uk

${ }^{\wedge}$ In memorium, deceased on 6th February 2019

${ }^{3}$ Clinical Trials Centre, Ground Floor, Winston Churchill Wing, St Mary's Hospital, Praed Street, London W2 1NY, UK

Full list of author information is available at the end of the article

\section{Background}

In the UK, opt-out antenatal HIV-1/2 (hereafter referred to as HIV) screening, combination antiretroviral treatment (cART) and infant formula feeding have successfully 
reduced rates of vertical transmission of HIV from $25 \%$ in 1993 [1], to the present national rate of $<0.5 \%$ [2-4]. In recent years, the majority of pregnant women living with HIV (WLWH) in the UK conceive on cART and maintain HIV suppression throughout pregnancy [4]. However, as recently as 2015-2016, 30\% of pregnant WLWH in the UK were still initiating cART during pregnancy [5].

Guidance regarding the timing of cART initiation and the class of compounds used during pregnancy has evolved over the study period and continue to vary between guidelines [6-9]. British HIV Association (BHIVA) guidelines recommend that if maternal plasma viral load (pVL) is $>100,000$ copies $/ \mathrm{mL}$ and/or CD4+ count is $<200$ cells $/ \mu \mathrm{L}$, cART should be initiated within the first trimester, and that all women should have commenced cART by 24 weeks' gestation [10]. Women presenting with untreated HIV beyond 28 weeks' gestation should initiate cART immediately, and if $\mathrm{pVL}$ is $>100,000$ copies $/ \mathrm{mL}$, a three- or four-drug regimen including raltegravir or dolutegravir is recommended. Read et al. demonstrated that delaying the initiation of cART beyond 26.3 weeks' gestation when baseline pVL is $<10,000$ copies $/ \mathrm{mL}$, or beyond 20.4 weeks' gestation when baseline pVL is $>100,000$ copies $/ \mathrm{mL}$, was associated with a reduced likelihood of achieving $\mathrm{pVL}<50$ copies/mL by delivery [11].

The rationale behind recommending the initiation of integrase strand transferase inhibitor (INSTI)-based cART, especially later in pregnancy, is the presumption that a more rapid reduction in maternal pVL will result in a higher chance of having an undetectable maternal pVL by delivery, with subsequent lower rates of perinatal HIV acquisition. Maternal viral burden is a strong predictor of perinatal HIV transmission, with a vertical transmission risk of $63 \%$ when untreated maternal pVL is $>100,000$ copies $/ \mathrm{mL}$ during pregnancy and at delivery [12], compared to $0.1 \%$ when maternal $\mathrm{pVL}$ is $<50$ copies $/ \mathrm{mL}$ on cART [2]. The risk of vertical transmission increases with shorter periods on cART prior to delivery: $3.5 \%$ with $>16$ weeks of cART and $9 \%$ in women who initiate cART $<4$ weeks prior to delivery [13]. However, the reductions in HIV vertical transmission are only partly explained by reductions in maternal pVL: firstly, in ACTG 076, maternal pVL at delivery in women initiating zidovudine monotherapy during pregnancy was only $0.24 \log _{10}$ HIV RNA copies/mL lower than in the placebo group, but HIV vertical transmission reduced by $67 \%$ in the zidovudine group $[14,15]$. Secondly, a single-dose of nevirapine administered at the onset of labour was capable of reducing HIV vertical transmission by nearly $50 \%$ [16] compared to zidovudine monotherapy initiated during labour. Given these findings, the reduction in vertical transmission in WLWH on cART during pregnancy can be considered to be the result of both treatment as prevention and infant peri-exposure prophylaxis.

Observational studies suggest that in the absence of cART and in exclusively formula-fed babies, two-thirds of HIV vertical transmissions occur during the intrapartum period [17]. However, in the cART era, $80 \%$ of HIV vertical transmission is thought to occur during the later stages of the antepartum period, prior to the onset of labour [18]. For women with untreated HIV infection, strategies that rapidly suppress maternal pVL during pregnancy are desirable, although the evidence that this directly translates into fewer HIV vertical transmissions is not yet available.

Modelling and clinical studies have demonstrated that when three or more antiretroviral drugs are initiated, a rapid exponential decline in pVL occurs in the first 6-14 days $[19,20]$, followed by a slower, second phase exponential decline, before pVL suppression [19, 21]. Choice of cART has been shown to affect time to viral suppression, notably with INSTI-based regimens achieving viral suppression significantly faster than other drug classes [22, 23].

The primary aim of our study was to investigate the factors associated with a faster first-phase plasma HIV RNA decay in women initiating cART during pregnancy. Secondary aims included investigating factors associated with an increased likelihood of having an undetectable pVL by 36 weeks' gestation (given that in the UK, recommendations for mode of delivery are guided by maternal pVL at 36 weeks' gestation [10] and investigating differences in HIV- and obstetric-related parameters when stratified by antiretroviral third agent class.

\section{Methods}

\section{Study setting and ethical considerations}

We conducted a retrospective case note review of all women initiating cART in pregnancy at HIV tertiary centres in south England, United Kingdom. The overall study was conducted between August 2001 and February 2018 to avoid bias, but the actual start dates varied according to site. All data were obtained as part of routine clinical care, anonymised at site, and then collated centrally for analysis. As per the National Research Ethics Service guidelines [24], additional patient consent and ethical approval were not required.

\section{Eligibility criteria}

Inclusion criteria were any woman commencing or recommencing cART during the index pregnancy with a quantifiable $\mathrm{pVL}$ at baseline, and further evaluation on day 14 ( \pm 3 days) following cART initiation. Subjects were excluded if poor adherence to cART was reported by either the subject or clinician. 


\section{Data collection}

Clinical data collected included baseline demographics, HIV-specific parameters (cART history, CD4+ T cell count and pVL during index pregnancy) and obstetric and infant specific information (estimated due date and actual delivery date). Aggregate level data on infant HIV infection status (where available) was provided by the National Surveillance of HIV in Pregnancy and Childhood [25].

\section{Outcome measures}

The primary outcome was first-phase plasma HIV RNA half-life decay rate, 14 days after commencing cART. First phase HIV RNA half-life decay (T/2) was calculated using the formula: $n \times \log _{10} 0.5 / \log _{10}\left(\mathrm{VL}_{1} / \mathrm{VL}_{\mathrm{BL}}\right)$, where $n=$ number of days to $\mathrm{VL}_{1} ; \mathrm{VL}_{1}=$ plasma HIV RNA load measured 14 days following the initiation of cART and $\mathrm{VL}_{\mathrm{BL}}=$ plasma HIV RNA load measured prior to the initiation of cART. T/2 was only calculated where $\mathrm{VL}_{1}$ was quantifiable. In a secondary analysis, when $\mathrm{VL}_{1}$ was reported as $<50$ or $<20 \mathrm{HIV}$ RNA copies/mL at day 14 , a value of 49 or 19 HIV RNA copies/mL were imputed respectively, to enable an estimation of the slowest first phase $\mathrm{T} / 2$ in these women. Secondary outcomes were time taken to achieve undetectable maternal pVL (lower than the limits of quantification) and proportion of women with an undetectable pVL by 36 weeks' gestation and by delivery. Subjects who did not achieve an undetectable PVL were censored at delivery.

\section{Statistical analyses}

Descriptive statistics summarised variables using median (interquartile range) and total (percentage). For the purposes of this study, the impact of the three dual nucleos $(\mathrm{t})$ ide reverse transcriptase inhibitors (NRTIs) used were considered equal. In subjects on quadruple therapy comprising dual NRTIs, an INSTI and a protease inhibitor (PI), T/2 was presumed to reflect the INSTI component.

Maternal $\mathrm{pVL}$ of $<50$ copies $/ \mathrm{mL}$ were regarded as undetectable, including those measured between 20 and 49 copies $/ \mathrm{mL}$. All quantifiable $\mathrm{pVL} \geq 20$ copies $/ \mathrm{mL}$ were included when calculating $\mathrm{T} / 2$. Time taken to achieve an undetectable pVL was calculated assuming that the date an undetectable pVL was achieved was the mid-point between the last detectable and first undetectable pVL.

Regression analysis was performed to investigate factors associated with faster $\mathrm{T} / 2$ (linear regression analysis) and with having an undetectable pVL at 36 weeks' gestation (logistic regression analysis). Kruskall-Wallis test was used to assess whether HIV- and obstetric- related parameters differed by antiretroviral third agent class. Mann-Whitney test (with Bonferroni correction) was then used to compare the parameters between antiretroviral third agent class. Fisher's exact test was used to assess whether the proportions of women with undetectable pVL at 36 weeks' gestation and at delivery differed by antiretroviral third agent class. All statistical analyses were conducted using SPSS version 24 (IBM Corp, Armonk, NY, US). Statistical significance was defined as $<0.05$ throughout.

\section{Results}

Of the 221 pregnant women at 11 participating HIV centres who initiated cART during the index pregnancy and had sufficient data for analysis, 192 had a detectable pVL after 14 days therapy. 29 women had $\mathrm{VL}_{1}<50$ copies/mL and are described separately.

\section{Baseline characteristics}

Baseline characteristics of the 192 women included in the main analysis are described in Table $1.83 .3 \%$ were Black African/Caribbean, 98.5\% identified heterosexual intercourse as their route of HIV acquisition, 63.5\% were cART-naïve and median $\mathrm{CD}^{+}$count prior to initiating cART (baseline) was 339 cells/ $\mu \mathrm{L}$ (Table 1). 126 (65.6\%) had pre-cART (baseline) plasma HIV RNA $<30,000$ copies/mL, 37 (19.3\%) between 30,000 and 100,000 HIV RNA copies/mL and 29 (15.1\%) had baseline plasma HIV RNA $>100,000$ copies/mL. 91\% of women commenced cART before 28 weeks' gestation: 181 (94.3\%) women initiated a dual NRTI backbone plus a third agent, 11 (5.7\%) initiated abacavir, lamivudine and zidovudine (ABC/3TC/AZT) (Table 1) and seven (3.6\%) initiated quadruple cART. Amongst the 192 women included in the main analysis, pVL fell by a median of $1.8 \log _{10}$ HIV RNA copies/mL 14 days after initiating cART, and median $\mathrm{T} / 2$ was 2.5 days (Table 1 ).

\section{Factors associated with first-phase plasma HIV RNA half-life decay}

Univariate linear regression analysis demonstrated that lower baseline CD4+T-cell count, higher $\mathrm{VL}_{\mathrm{BL}}$ and INSTI-based cART were associated with faster viral decay (shorter T/2) (Table 2). However, in multivariable regression analysis, only higher $\mathrm{VL}_{\mathrm{BL}}$ remained independently associated with shorter $\mathrm{T} / 2(-0.61$ days per 1 $\log _{10}$ plasma HIV RNA higher, $\mathrm{p}<0.001$ ) (Table 2).

\section{Factors associated with having an undetectable maternal plasma viral load at $\mathbf{3 6}$ weeks' gestation}

In multivariate logistic regression analysis, the following factors were associated with a higher probability of having an undetectable maternal pVL by 36 weeks' gestation: lower maternal pVL 14 days after initiating cART (odds ratio (OR) $0.05,95 \%$ confidence interval (CI) $0.01,0.19$ ) 
Table 1 Baseline characteristics, CART regimens and responses of the women who commenced cART during pregnancy

\begin{tabular}{|c|c|c|}
\hline Values are median (IQR) or total (\%) & $\begin{array}{l}\text { Women initiating cART during index } \\
\text { pregnancy and with a quantifiable HIV RNA } \\
\text { at day } 14 \\
(n=192)\end{array}$ & $\begin{array}{l}\text { Women initiating cART during index } \\
\text { pregnancy and with HIV RNA below the limits } \\
\text { of quantification at day } 14 \\
(n=29)\end{array}$ \\
\hline Age (years) & $31.0(26.5,34.0)$ & $31.0(25.5,36.0)$ \\
\hline Black African and/or Caribbean ethnicity & $160(83.3)$ & $26(89.7)$ \\
\hline HIV acquired via heterosexual intercourse & $189(98.5)$ & $28(96.6)$ \\
\hline Hepatitis B and/or C co-infection & $2(1.0)$ & $4(13.7)$ \\
\hline Received cART previously & $70(36.5)$ & $9(31.0)$ \\
\hline Gestational age when CART initiated, weeks & $20.8(16.9,24.4)$ & $21.9(19.0,24.3)$ \\
\hline Baseline CD4+ ${ }^{+}$-cell count, cells/ $\mu \mathrm{L}$ & $339(212,481)$ & $520(334-637)$ \\
\hline Baseline plasma HIV RNA, $\log _{10} c o p i e s / m L$ & $4.2(3.8,4.7)$ & $3.1(2.9-3.6)$ \\
\hline $\begin{array}{l}\text { Plasma HIV RNA } 14 \text { days after initiating CART, } \\
\log _{10} \text { copies/mL }\end{array}$ & $2.4(2.1,2.9)$ & All $<1.7$ \\
\hline First-phase HIV RNA half-life decay, days & $2.5(2.1,3.0)$ & $2.9(2.2,3.6)$ \\
\hline $\begin{array}{l}\text { Women with } \mathrm{pVL}<50 \text { copies } / \mathrm{mL} \text { at } 36 \text { weeks' } \\
\text { gestation }\end{array}$ & $139(72.4)$ & $29(100)$ \\
\hline Women with $\mathrm{pVL}<50$ copies $/ \mathrm{mL}$ at delivery & $163(84.9)$ & $29(100)$ \\
\hline Gestational age at delivery, weeks & $39.1(38.0,40.4)$ & $39.0(38.0,40.0)$ \\
\hline \multicolumn{3}{|l|}{ CART regimen used } \\
\hline $\mathrm{ABC} / 3 \mathrm{TC} / \mathrm{AZT}$ & $11(5.7)$ & $3(10.3)$ \\
\hline Dual NRTI backbone & $181(94.3)$ & $26(89.7)$ \\
\hline$A Z T+3 T C$ & $75(39.1)$ & $11(37.9)$ \\
\hline$A B C+3 T C$ & $41(21.4)$ & $6(20.7)$ \\
\hline $\mathrm{TDF}+\mathrm{FTC}$ & $65(33.9)$ & $9(31.0)$ \\
\hline Dual NRTI backbone + PI & $132(68.8)$ & $20(69.0)$ \\
\hline Atazanavir/ritonavir & $60(31.1)$ & $9(31.0)$ \\
\hline Darunavir/ritonavir & $11(5.7)$ & $1(3.4)$ \\
\hline Lopinavir/ritonavir & $50(26.0)$ & $3(10.3)$ \\
\hline Saquinavir/ritonavir & $11(5.7)$ & $7(24.1)$ \\
\hline Dual NRTI backbone + NNRTI & $32(16.7)$ & $2(6.9)$ \\
\hline Nevirapine & $26(13.5)$ & $2(6.9)$ \\
\hline Efavirenz & $5(2.6)$ & 0 \\
\hline Rilpivirine & $1(0.5)$ & 0 \\
\hline Dual NRTI backbone + INSTI & $17(8.9)$ & $4(13.8)$ \\
\hline Raltegravir & $11(5.7)$ & $1(3.4)$ \\
\hline Dolutegravir & $6(3.1)$ & $3(10.3)$ \\
\hline \multicolumn{3}{|l|}{ Infant HIV status at birth } \\
\hline HIV negative & $150(78.1)$ & $21(72.4)$ \\
\hline Data not available & $42(21.9)$ & $8(27.6)$ \\
\hline
\end{tabular}

Baseline characteristics, antiretroviral treatment regimens and responses of the 221 women living with HIV, who commenced combination antiretroviral therapy during index pregnancy

IQR interquartile range, $C A R T$ combination antiretroviral treatment, $A B C$ abacavir, $3 T C$ lamivudine, $A Z T$ zidovudine, TDF tenofovir disoproxil fumarate, $F T C$ emtricitabine, PI protease inhibitor, NNRTI non-nucleoside reverse transcriptase inhibitor, INSTI integrase strand transferase inhibitor

and earlier gestational age when cART was initiated (OR $0.66,95 \%$ CI 0.58, 0.76) (Table 3).

\section{Differences in HIV- and obstetric-related parameters} when stratified according to antiretroviral third agent class $\mathrm{T} / 2$ was significantly shorter in women commenced on INSTIs compared to those commenced on PIs, non-nucleoside reverse transcriptase inhibitor (NNRTIs), and $\mathrm{ABC} / 3 \mathrm{TC} / \mathrm{AZT}(\mathrm{p}<0.001, \mathrm{p}<0.001$ and $\mathrm{p}=0.03$, respectively) (Table 4). $\mathrm{T} / 2$ was significantly longer in women commenced on PIs compared to NNRTIs, $\mathrm{p}=0.03$ (Table 4).

Women who initiated an INSTI had significantly higher $\mathrm{VL}_{\mathrm{BL}}$ compared to women initiating PIs and 
Table 2 Linear regression analysis investigating factors associated with first-phase HIV RNA half-life decay

\begin{tabular}{|c|c|c|c|c|}
\hline & \multicolumn{2}{|l|}{ Univariate analysis } & \multicolumn{2}{|l|}{ Multivariate analysis } \\
\hline & Change $(95 \% \mathrm{Cl})^{\mathrm{a}}$ & $p$-value & Change $(95 \% \mathrm{Cl})^{\mathrm{a}}$ & $p$-value \\
\hline Maternal age, per 1-year higher & $0.02(-0.01,0.05)$ & 0.24 & & \\
\hline Black African/Caribbean ethnicity & $-0.13(-0.61,0.35)$ & 0.17 & & \\
\hline HIV acquired via heterosexual intercourse & $1.08(-0.34,2.51)$ & 0.14 & & \\
\hline Previous cART use & $-0.08(-0.45,0.29)$ & 0.67 & & \\
\hline Baseline $\mathrm{CD}^{+}{ }^{+} \mathrm{T}$-cell count, per 10 cells/ $\mu \mathrm{L}$ increase & $0.01(0.00,0.02)$ & 0.003 & $0.00(-0.01,0.01)$ & 0.47 \\
\hline Baseline plasma HIV RNA, per $1 \log _{10}$ copies/mL higher & $-0.71(-0.97,-0.46)$ & $<0.001$ & $-0.611(-0.918,-0.305)$ & $<0.001$ \\
\hline Gestational age when CART was started, per 1-week higher & $-0.02(-0.05,0.01)$ & 0.21 & & \\
\hline \multicolumn{5}{|l|}{ Antiretroviral third agent class } \\
\hline $\mathrm{Pl}$ & $0.34(-0.04,0.72)$ & 0.08 & & \\
\hline NNRTI & $-0.27(-0.74,0.21)$ & 0.27 & & \\
\hline INSTI & $-0.84(-1.46,-0.23)$ & 0.007 & $-0.365(-0.982,0.251)$ & 0.24 \\
\hline
\end{tabular}

Table 3 Logistic regression investigating factors associated with having an undetectable maternal pVL by 36 weeks' gestation

\begin{tabular}{ll}
\hline & Odds ratio $\mathbf{( 9 5 \% ~ C l )}$ \\
\hline Maternal age, years & $0.99(0.90,1.08)$ \\
Baseline CD4 ${ }^{+}$T-cell count, cells/ $\mu \mathrm{L}$ & $1.00(0.99,1.05)$ \\
Baseline plasma HIV RNA, $\log _{10}$ copies/mL & $0.88(0.28,2.81)$ \\
Plasma HIV RNA 14 days after initiating CART, $\log _{10}$ & $0.05(0.01,0.19)$ \\
$\quad$ copies/mL & $0.66(0.58,0.76)$ \\
\hline Gestational age when cART was started, weeks & \\
\hline
\end{tabular}

Multivariate logistic regression analysis investigating factors associated with having an undetectable maternal plasma viral load by 36 weeks' gestation

$\mathrm{Cl}$ confidence interval, $C A R T$ combination antiretroviral treatment, $p V L$ plasma viral load

$\mathrm{ABC} / 3 \mathrm{TC} / \mathrm{AZT}(\mathrm{p}<0.001$ and $\mathrm{p}<0.001$, respectively), while women commenced on $\mathrm{ABC} / 3 \mathrm{TC} / \mathrm{AZT}$ had significantly lower $\mathrm{VL}_{\mathrm{BL}}$ and higher baseline $\mathrm{CD} 4+$ counts compared to women commenced on PIs and NNRTIs (Table 4). Women who initiated NNRTIs had lower baseline CD4 compared to women initiated on PIs. While there was no statistically significant difference in the gestational age at which cART was commenced when stratified according to the three-third agent antiretroviral classes and ABC/3TC/AZT (Table 4), higher $\mathrm{VL}_{\mathrm{BL}}$ was significantly associated with earlier gestational age when cART was initiated, $\mathrm{p}=0.02$.

Between the four groups, the overall time to an undetectable pVL was numerically shorter in women commenced on INSTIs, but statistically only approached significance when comparing women initiating INSTIs (27.5 days) and NNRTIs (51.5 days), $\mathrm{p}=0.05$ (Table 4 ).
An undetectable pVL was seen in $72.9 \%$ of all women by 36 weeks gestational age with broadly similar rates across the three antiretroviral third agent classes: PIs $72.0 \%$, NNRTIs $65.6 \%$ and INSTIs $76.5 \%$ (Table 4). 164 (85.4\%) women had an undetectable pVL by delivery: PIs $85.6 \%$, NNRTIs $75.0 \%$ and INSTIs $94.1 \%$ (Table 4). All women who initiated ABC/3TC/AZT had undetectable pVL at both 36 weeks' gestation and delivery. Statistically, the proportions of women with undetectable pVL at 36 weeks' gestation and at delivery did not differ significantly by antiretroviral third agent class $(\mathrm{p}=0.13$ and $\mathrm{p}=0.17$, respectively).

\section{Women with $\mathrm{pVL}<50$ copies $/ \mathrm{mL}$ at day 14 following cART initiation}

Baseline characteristics for the 29 women with $\mathrm{VL}_{1}<50$ copies/mL were broadly similar to the 192 women included in the main analysis (Table 1). However, this cohort of 29 women had significantly higher baseline $\mathrm{CD} 4+$ count $(\mathrm{p}=0.001)$, lower $\mathrm{VL}_{\mathrm{BL}}(\mathrm{p}<0.001)$, a higher proportion with Hepatitis $B$ co-infection $(\mathrm{p}=0.007)$, and all women had $\mathrm{VL}_{\mathrm{BL}}<30,000$ copies $/ \mathrm{mL}$. The longest estimated $\mathrm{T} / 2$ in this cohort of 29 women was similar to the $\mathrm{T} / 2$ seen in the subgroup of women included in the main analysis with $\mathrm{VL}_{\mathrm{BL}}<30,000$ copies $/ \mathrm{mL}, \mathrm{p}=0.354$.

\section{Infant HIV infection rates}

Infant HIV infection status was established for 171/221. All 171/221 infants were negative by molecular HIV testing at birth. For the remaining 50/221, infection status was not available. Although data on infant HIV peri-exposure prophylaxis were not available, each centre managed infants according to the contemporaneous 
Table 4 HIV- and obstetric-related parameters, stratified according to antiretroviral third agent class

\begin{tabular}{|c|c|c|c|c|c|}
\hline & $\begin{array}{l}\mathrm{PI} \\
n=132\end{array}$ & $\begin{array}{l}\text { NNRTI } \\
n=32\end{array}$ & $\begin{array}{l}\text { INSTI } \\
n=17\end{array}$ & $\begin{array}{l}\mathrm{ABC} / 3 \mathrm{TC} / \mathrm{AZT} \\
n=11\end{array}$ & p-values (with Bonferroni correction) \\
\hline HIV RNA half-life decay, days & $2.6(1.6-11.5)$ & $2.3(1.4-5.3)$ & $1.8(1.1-6.0)$ & $2.6(1.8-10.3)$ & $\begin{array}{l}x^{2}(3)=30.92, p<0.001 \\
\text { PI vs NNRTI, } p=0.03 \\
\text { PI vs INSTI, } p<0.001 \\
\text { PI vs ABC/3TC/AZT, } p=0.87 \\
\text { NNRTI vs INSTI, } p<0.001 \\
\text { NNRTI vs ABC/3TC/AZT, } p=0.32 \\
\text { INSTI vs ABC/3TC/AZT, } p=0.03\end{array}$ \\
\hline Baseline $\mathrm{pVL}, \log _{10}$ copies $/ \mathrm{mL}$ & $4.2(2.5-5.8)$ & $4.3(2.8-5.4)$ & $5.0(4.0-5.8)$ & $3.8(2.9-4.5)$ & $\begin{array}{l}x^{2}(3)=28.14, p<0.001 \\
\text { PI vs NNRTI, } p=0.13 \\
\text { PI vs INSTI, } p<0.001 \\
\text { PI vs ABC/3TC/AZT, } p=0.04 \\
\text { NNRTI vs INSTI, } p=0.18 \\
\text { NNRTI vs ABC/3TC/AZT, } p=0.03 \\
\text { INSTI vs ABC/3TC/AZT, } p<0.001\end{array}$ \\
\hline Baseline CD4 ${ }^{+}$T-cell count, cells $/ \mu \mathrm{L}$ & $359(63-1136)$ & $207(30-848)$ & $215(10-700)$ & $574(290-1008)$ & $\begin{array}{l}x^{2}(3)=31.20, p<0.001 \\
\text { PI vs NNRTI, } p<0.001 \\
\text { PI vs INSTI, } p=0.28 \\
\text { PI vs ABC/3TC/AZT, } p=0.03 \\
\text { NNRTI vs INSTI, } p=0.56 \\
\text { NNRTI vs ABC/3TC/AZT, } p<0.001 \\
\text { INSTI vs ABC/3TC/AZT, } p=0.06\end{array}$ \\
\hline $\begin{array}{l}\text { Gestational age when cART was started, } \\
\text { weeks }\end{array}$ & $21.2(5.7-39.6)$ & $18.9(4.9-34.0)$ & $17.6(8.1-34.4)$ & $21.9(10.9-24.0)$ & $x^{2}(3)=3.67, p=0.299$ \\
\hline $\begin{array}{l}\text { pVL } 14 \text { days after cART was initiated, } \log _{10} \\
\text { HIV RNA copies/mL }\end{array}$ & $2.5(1.5-4.1)$ & $2.5(1.8-3.6)$ & $2.4(1.5-4.3)$ & $1.9(1.7-2.9)$ & $x^{2}(3)=6.94, p=0.074$ \\
\hline $\begin{array}{l}\text { Time taken to reach } \mathrm{pVL}<50 \text { copies } / \mathrm{mL} \text {, } \\
\text { days }^{\mathrm{a}}\end{array}$ & $51.5(7-174)$ & $51.5(21-188)$ & $27.5(6-121)$ & $32.5(21-63)$ & $\begin{array}{l}x^{2}(3)=12.99, p=0.005 \\
\text { PI vs NNRTI, } p=0.63 \\
\text { PI vs INSTI, } p=0.09 \\
\text { PI vs ABC/3TC/AZT, } p=0.07 \\
\text { NNRTI vs INSTI, } p=0.05 \\
\text { NNRTI vs ABC/3TC/AZT, } p=0.35 \\
\text { INSTI vs ABC/3TC/AZT, } p=0.45\end{array}$ \\
\hline $\begin{array}{l}\text { Women with } \mathrm{pVL}<50 \text { copies } / \mathrm{mL} \text { at } \\
36 \text { weeks' gestation }\end{array}$ & $95(72.0)$ & $21(65.6)$ & $13(76.5)$ & $11(100)$ & $p=0.13$ \\
\hline $\begin{array}{l}\text { Women with } \mathrm{pVL}<50 \text { copies } / \mathrm{mL} \text { at } \\
\text { delivery }\end{array}$ & $113(85.6)$ & $24(75.0)$ & $16(94.1)$ & $11(100)$ & $p=0.17$ \\
\hline Values are median (range) or total (\%) & & & & & \\
\hline
\end{tabular}

PI protease inhibitor, NNRTI non-nucleoside reverse transcriptase inhibitor, INSTI integrase strand transferase inhibitor, $A B C$ abacavir, $3 T C$ lamivudine, $A Z T$ zidovudine, $C A R T$ combination antiretroviral treatment, $p V L$ plasma viral load

a Only women who achieved plasma viral loads lower than the limits of quantification prior to delivery are included

version of the BHIVA guidelines on the management of HIV infection in pregnancy.

\section{Discussion}

In this study, higher baseline plasma viral load $\left(\mathrm{VL}_{\mathrm{BL}}\right)$ was the sole independent predictor of faster first-phase HIV RNA decay. Secondly, lower maternal pVL 14 days after cART initiation and earlier gestational age when cART was initiated independently predicted a higher likelihood of having an undetectable maternal pVL at 36 weeks' gestation.

Overall, women in this cohort experienced a median $1.8 \log _{10}$ copies/mL decline in $\mathrm{pVL} 14$ days after initiating cART, with the shortest $\mathrm{T} / 2$ and thus, largest HIV RNA decline seen in women on INSTIs (despite small numbers of women on INSTIs), in keeping with the DolPHIN-1 (Dolutegravir in pregnant $\underline{\text { HIV }}$ mothers and their neonates) [26] study results demonstrating superior virological responses with dolutegravir-based cART compared to efavirenz-based cART when initiated in late pregnancy in low and middle-income settings. This strengthens the recommendation for assessing response to cART at this early stage and emphasises that clinicians and patients should expect around a $99 \%$ reduction in maternal pVL after 2 weeks of cART. Less convincing reductions in $\mathrm{pVL}$ at day 14, regardless of third agent in the cART regime, should be a cause for concern. Current BHIVA guidelines recommending all women should have started cART by 
24 weeks' gestation are based on the results published by Read et al. [11]. However, it is important to note that cART regimens in this study only included PIs, NNRTIs and ABC/3TC/AZT and did not include INSTIbased cART. Given the faster rate of HIV RNA declines in women on INSTIs as demonstrated in our study and other published data [26], the latest gestational age before which women on INSTI-based cART should have commenced cART will need to be explored in future studies.

Excluding $\mathrm{ABC} / 3 \mathrm{TC} / \mathrm{AZT}$ due to small subject numbers, only $66-77 \%$ of women on PIs, NNRTIs and INSTIs had undetectable pVL at 36 weeks' gestation, when obstetric delivery plans are usually finalised. Of these women, those on INSTIs had the highest proportion of undetectable $\mathrm{pVL}$ by delivery and a shorter time to an undetectable $\mathrm{pVL}$, despite starting with significantly higher $\mathrm{VL}_{\mathrm{BL}}$, mirroring the findings seen in randomised trials of cART initiation during pregnancy performed in low and middle-income countries (DolPHIN-2 study [27]: dolutegravir versus efavirenz-based cART and the National Institute of Child Health and Human Development P1081 study [28]: raltegravir versus efavirenz-based cART). At present, INSTIs are considered the preferred antiretroviral third agent for women presenting late in pregnancy, yet in our study cohort, gestational age when cART was initiated was numerically earlier with INSTIs than with the other classes, reflecting the recommendation to initiate cART earlier in women with high baseline pVL. Over $90 \%$ of women in our study initiated cART before 28 weeks' gestation but the low overall maternal CD4+ counts prior to initiating cART indicates that many of these women were presenting late in the course of their HIV infection.

While the small number of women who initiated $\mathrm{ABC} / 3 \mathrm{TC} / \mathrm{AZT}$ in pregnancy all had an undetectable $\mathrm{pVL}$ at delivery, they had lower $\mathrm{VL}_{\mathrm{BL}}$ and higher CD4+ counts than women who initiated PIs and NNRTIs, consistent with a targeted approach for initiating $\mathrm{ABC} / 3 \mathrm{TC} / \mathrm{AZT}$. The results seen in this subgroup of women should therefore not be extrapolated to women with higher $\mathrm{VL}_{\mathrm{BL}}$ and lower baseline $\mathrm{CD} 4+$ counts.

Limitations of our study include the small number of subject initiating INSTIs, preventing statistical analysis of the clinical effects between the individual INSTI agents, and the long data collection period, meaning that data were collected and analysed for antiretroviral drugs that are now rarely used or commenced in the UK. While the exclusion of subjects with poor adherence reported by either the subject or clinician was necessary to enable the accurate calculation of the first-phase HIV RNA half-life decay during treatment, this may have led to inadvertent subject selection bias. Recent modelling studies have since suggested that on
INSTI-based cART regimens, the original first phase $\mathrm{T} / 2$ described may be replaced by a split first phase (phase 1a and 1b), followed by the second phase which starts at a lower plasma viral load than the start of the second phase with PI and NNRTIs [29]. We were unable to explore this concept in our study.

The findings of this observational study support the use of INSTIs when initiating cART in pregnancy, especially in women presenting later in pregnancy and/or with higher $\mathrm{VL}_{\mathrm{BL}}$ on the basis of achieving rapid reductions in $\mathrm{pVL}$ and an undetectable viral load at delivery. However, it is important to note that non-INSTI-based regimens also performed well. Whilst awaiting further data on the higher incidence $(0.3 \%)$ of neural tube defects in infants born to women conceiving on dolutegravir [30], there may well be a decrease in the use of dolutegravir, and possibly INSTIs as a whole, especially when initiating cART in the first trimester of pregnancy. In the meantime, other third agent antiretroviral drugs with more data on safety and efficacy in pregnancy that perform well in pregnancy are likely to be used in preference.

\section{Conclusions}

Higher baseline maternal pVL was the sole independent factor associated with faster HIV RNA decay 14 days after cART initiation. Lower maternal pVL 14 days after initiating cART, but not lower baseline maternal pVL, was associated with a higher chance of having an undetectable maternal $\mathrm{pVL}$ at 36 weeks' gestation.

\section{Abbreviations}

ABC/3TC/AZT: Abacavir/lamivudine/zidovudine; BHIVA: British HIV Association; CART: Combination antiretroviral treatment; DoIPHIN study: Dolutegravir in pregnant HIV mothers and their neonates study; INSTI: Integrase strand transferase inhibitor; NRTIs: Nucleos(t)ide reverse transcriptase inhibitors; NNRTIs: Non-nucleoside reverse transcriptase inhibitors; PIs: Protease inhibitors; pVL: Plasma viral load; T/2: First phase HIV RNA half-life decay; $\mathrm{VL}_{1}$ : Plasma HIV RNA load measured 14 days following the initiation of $C A R T ; V_{B L}$ : Plasma HIV RNA load measured prior to the initiation of CART; WLWH: Women living with HIV.

\section{Acknowledgements}

Department of Genitourinary Medicine \& HIV, Queen Elizabeth Hospital, London, UK: Judith Russell; Department of Genitourinary Medicine \& HIV, Central Middlesex Hospital, London, UK: Siobhan Murphy, Paola Hafner; Statistical Advisory Service, Imperial College London: Joseph Eliahoo.

\section{Authors' contributions}

GPT conceptualised the design of the study; JA and GPT designed the study data collection proforma; JA, HP, KF, YG, FPF, REG, SP, MP, BCW, RS, SR, DAH, SC, LS, RM, AH, AVN, MR and GPT had major roles in the acquisition of the data; JA and GPT performed the statistical analysis; JA and GPT interpreted the data results; JA and GPT drafted and revised the initial manuscript; all authors contributed and revised the manuscript for intellectual content. All authors read and approved the final manuscript.

\section{Funding}

None. 


\section{Availability of data and materials}

The datasets generated and analysed during the current study are not publicly available but are available from the corresponding author upon reasonable request.

\section{Ethics approval and consent to participate}

Not applicable.

\section{Consent for publication}

Not applicable.

\section{Competing interests}

The authors declare that they have no competing interests.

\section{Author details}

1 Section of Virology, Department of Infectious Disease, Faculty of Medicine, Imperial College London, London W2 1PG, UK. ${ }^{2}$ Department of Genitourinary Medicine, St Mary's Hospital, Imperial College Healthcare NHS Trust, London W2 1NY, UK. ${ }^{3}$ Clinical Trials Centre, Ground Floor, Winston Churchill Wing, St Mary's Hospital, Praed Street, London W2 1NY, UK. ${ }^{4}$ National Surveillance of HIV in Pregnancy and Childhood, UCL Great Ormond Street Institute of Child Health, 30 Guildford Street, Holborn, London WC1N 1EH, UK. ${ }^{5}$ The Holborn Medical Centre, 64-66 Lamb's Conduit Street, Holborn, London WC1N 3NA, UK. ${ }^{6}$ Royal Sussex County Hospital, Eastern Road, Brighton BN2 5BE, UK. ${ }^{7}$ Homerton University Hospital Foundation Trust, Homerton Row, Clapton, London E9 6SR, UK. ${ }^{8}$ Royal Free Hospital, Pond Street, London NW3 2QG, UK. ${ }^{9}$ Mortimer Market Centre, Capper Street, Bloomsbury, London WC1E 6JB, UK. ${ }^{10}$ Chelsea and Westminster Hospital NHS Foundation Trust, 369 Fulham Road, Chelseas, London SW10 9NH, UK. ${ }^{11}$ The Royal London Hospital, Whitechapel Road, Whitechapel, London E1 1FR, UK. ${ }^{12}$ Guy's and St Thomas' NHS Foundation Trust, Westminster Bridge Road, London SE1 7EH, UK. ${ }^{13}$ University Hospital Lewisham, Lewisham High Street, London SE13 6LH, UK.

Received: 22 May 2020 Accepted: 4 July 2020

Published online: 13 July 2020

\section{References}

1. Duong T, Ades AE, Gibb DM, Tookey PA, Masters J. Vertical transmission rates for HIV in the British Isles: estimates based on surveillance data. BMJ. 1999;319(7219):1227-9.

2. Townsend CL, Cortina-Borja M, Peckham CS, de Ruiter A, Lyall H, Tookey PA. Low rates of mother-to-child transmission of HIV following effective pregnancy interventions in the United Kingdom and Ireland, 2000-2006. AIDS. 2008;22(8):973-81.

3. Townsend CL, Byrne L, Cortina-Borja M, Thorne C, De Ruiter A, Lyall H, et al. Earlier initiation of ART and further decline in mother-to-child HIV transmission rates, 2000-2011. AIDS. 2014;28(7):1049-57.

4. Peters H, Francis K, Sconza R, Horn A, Peckham CS, Tookey PA, et al. UK mother-to-child HIV transmission rates continue to decline: 2012-2014. Clin Infect Dis. 2017;64(4):527-8.

5. Peters $H$, Francis $K$, Horn A, Thorne $C$. Successes and emerging challenges in prevention of vertical HIV transmission in the UK \& Ireland. 2019; https ://www.ucl.ac.uk/nshpc/sites/nshpc/files/peters_successes_and_chall enges_pmtct.pdf.

6. European AIDS Clinical Society. European AIDS Clinical Society (EACS) Guidelines. Version 9. 2017;72. http://www.eacsociety.org/guidelines/ eacs-guidelines/eacs-guidelines.html.

7. US Department of Health and Human Services. Recommendations for the Use of Antiretroviral Drugs in Pregnant Women with HIV Infection and Interventions to Reduce Perinatal HIV Transmission in the United States. AIDSinfo. 2017

8. Money D, Tulloch K, Boucoiran I, Caddy S, Yudin MH, Allen V, et al. Guidelines for the care of pregnant women living with HIV and interventions to reduce perinatal transmission: executive summary. J Obstet Gynaecol Canada. 2014;36(8):721-34.

9. Organization WH. Rapid advice: use of antiretroviral drugs for treating pregnant women and preventing HIV infection in infants. Geneva: WHO; 2009
10. Gilleece Y, et al. British HIV Association guidelines for the management of HIV in pregnancy and postpartum 2018. HIV Med. 2019;20:s2-85. https:// doi.org/10.1111/hiv.12720.

11. Read PJ, Mandalia S, Khan P, Harrisson U, Naftalin C, Gilleece Y, et al. When should HAART be initiated in pregnancy to achieve an undetectable HIV viral load by delivery? AIDS. 2012;26(9):1095-103.

12. Garcia PM, Kalish LA, Pitt J, Minkoff H, Quinn TC, Burchett SK, et al. Maternal levels of plasma human immunodeficiency virus type 1 RNA and the risk of perinatal transmission. N Engl J Med. 1999:341(6):394-402.

13. Hoffman RM, BlackV, Technau K, van der Merwe KJ, Currier J, Coovadia A, et al. Effects of highly active antiretroviral therapy duration and regimen on risk for mother-to-child transmission of HIV in Johannesburg, South Africa. J Acquir Immune Defic Syndr. 2010;54(1):35-41. http://www. pubmedcentral.nih.gov/articlerender.fcgi?artid=2880466\&tool=pmcen trez\&rendertype $=$ abstract.

14. Sperling RS. Maternal viral load, zidovudine treatment, and the risk of transmission of human immunodeficiency virus type 1 from mother to infant. Stud Fam Plann. 2006;335(22):1621-9.

15. Connor EM, Sperling RS, Gelber R, Kiselev P, Scott G, O'Sullivan MJ, et al. Reduction of maternal-infant transmission of human immunodeficiency virus type 1 with zidovudine treatment. Pediatric AIDS Clinical Trials Group Protocol 076 Study Group. N Engl J Med. 1994;331(18):1173-80.

16. Guay LA, Musoke P, Fleming T, Bagenda D, Allen M, Nakabiito C, et al. Intrapartum and neonatal single-dose nevirapine compared with zidovudine for prevention of mother-to-child transmission of HIV-1 in Kampala, Uganda: hIVNET 012 randomised trial. Lancet. 1999;354(9181):795-802.

17. Rouzioux C, Costagliola D, Burgard M, Blanche S, Mayaux MJ, Griscelli C, et al. Estimated Timing of Mother-to-Child Human Immunodeficiency Virus Type 1 (HIV-1) Transmission by Use of a Markov Model. Am J Epidemiol [Internet]. 1995;142(12):1330-7. http://aje.oxfordjournals.org/ content/142/12/1330.abstract?maxtoshow $=\& H I T S=10 \&$ hits $=10 \& R E$ SULTFORMAT = \&author $1=$ Rouzioux\%252C + C\%253B + \&andorexact title $=$ and\&andorexacttitleabs $=$ and\&andorexactfulltext $=$ and \&searc hid $=1 \&$ FIRSTINDEX $=0 \&$ fdate $=1 / 1 / 1995 \&$ tdate $=12 / 31 / 1995 \&$ res.

18. Magder LS, Mofenson L, Paul ME, Zorrilla CD, Blattner WA, Tuomala RE, et al. Risk factors for in utero and intrapartum transmission of HIV. J Acquir Immune Defic Syndr. 2005;38(1):87-95.

19. Perelson AS, Essunger $P, C a o$ Y, Vesanen M, Hurley A, Saksela K, et al. Decay characteristics of HIV-1-infected compartments during combination therapy. Nature. 1997;387(6629):188-91.

20. Stephan C, Baldauf HM, Barry J, Giordano FA, Bartholomae CC, Haberl A, et al. Impact of raltegravir on HIV-1 RNA and DNA forms following initiation of antiretroviral therapy in treatment-naive patients. J Antimicrob Chemother. 2014;69(10):2809-18.

21. Ding AA, Wu H. Relationships between antiviral treatment effects and biphasic viral decay rates in modeling HIV dynamics. Math Biosci. 1999;160(1):63-82.

22. Hoenigl M, Chaillon A, Moore DJ, Morris SR, Mehta SR, Gianella S, et al. Rapid HIV viral load suppression in those initiating antiretroviral therapy at first visit after HIV diagnosis. Sci Rep. 2016;6(1):1-5.

23. Lennox JL, DeJesus E, Lazzarin A, Pollard RB, Madruga JVR, Berger DS, et al. Safety and efficacy of raltegravir-based versus efavirenz-based combination therapy in treatment-naive patients with HIV-1 infection: a multicentre, double-blind randomised controlled trial. Lancet. 2009;374(9692):796-806.

24. Do I need NHS Ethics approval? [Internet]. [cited 2019 Sep 23]. Available from: http://www.hra-decisiontools.org.uk/ethics/.

25. National Surveillance of HIV in Pregnancy and Childhood - UCL - London's Global University. https://www.ucl.ac.uk/nshpc/.

26. Waitt C, Orrell C, Walimbwa S, Singh Y, Kintu K, Simmons B, et al. Safety and pharmacokinetics of dolutegravir in pregnant mothers with HIV infection and their neonates: a randomised trial (DoIPHIN-1 study). PLoS Med. 2019;16(9):e1002895.

27. Kintu K, Malaba TR, Nakibuka J, Papamichael C, Colbers A, Byrne K, et al. Dolutegravir versus efavirenz in women starting HIV therapy in late pregnancy (DolPHIN-2): an open-label, randomised controlled trial. Lancet HIV. 2020;7:e332-9.

28. João EC, Morrison RL, Shapiro DE, Chakhtoura N, Gouvèa MIS, de Lourdes BTM, et al. Raltegravir versus efavirenz in antiretroviral-naive pregnant women living with HIV (NICHD P1081): an open-label, randomised, controlled, phase 4 trial. Lancet HIV. 2020;7(5):e322-31. 
29. Cardozo EF, Andrade A, Mellors JW, Kuritzkes DR, Perelson AS, Ribeiro RM. Treatment with integrase inhibitor suggests a new interpretation of HIV RNA decay curves that reveals a subset of cells with slow integration. PLoS Pathog. 2017;13(7):e1006478.

30. Zash R, Holmes L, Diseko M, Jacobson DL, Brummel S, Mayondi G, et al. Neural-tube defects and antiretroviral treatment regimens in Botswana. N Engl J Med. 2019;381(9):827-40.

\section{Publisher's Note}

Springer Nature remains neutral with regard to jurisdictional claims in published maps and institutional affiliations.
Ready to submit your research? Choose BMC and benefit from:

- fast, convenient online submission

- thorough peer review by experienced researchers in your field

- rapid publication on acceptance

- support for research data, including large and complex data types

- gold Open Access which fosters wider collaboration and increased citations

- maximum visibility for your research: over $100 \mathrm{M}$ website views per year

At BMC, research is always in progress.

Learn more biomedcentral.com/submissions 